\title{
A Seven-year Follow-up Study of Patient Satisfaction with Three-implant-retained Mandibular Overdentures
}

\author{
Hisham S. ElGabry* \\ Department of Prosthodontics, National Research Center, MSA University, Cairo, Egypt
}

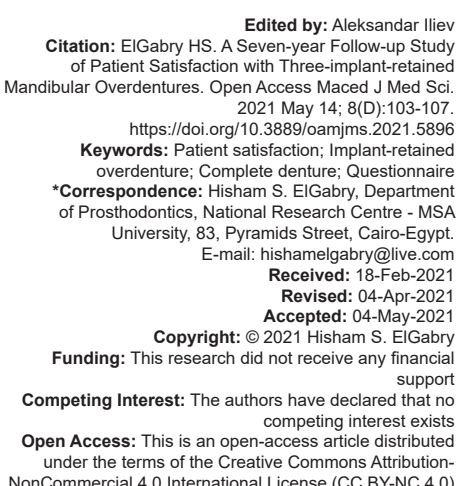

Edited by: Aleksandar lliev Edited by: Aleksandar lliev
Citation: ElGabry HS. A Seven-year Follow-up Study Citation: ElGabry HS. A Seven-year Follow-up Study Mandibular Overdentures. Open Access Maced J Med Sci. 2021 May 14; 8(D):103-107. https://doi.org/10.3889/oamjms.2021.5896 Keywords: Patient satisfaction; Implant-retained overdenture; Complete denture; Questionnaire *Correspondence: Hisham S. ElGabry, Department of Prosthodontics, National Research Centre - MSA University, 83, Pyramids Street, Cairo-Egypt. E-mail: hishamelgabry@live.com Received: 18-Feb-202 Revised: 04-Apr-2021 Copyright: ( ) 2021 Hisham S. ElG-2021 Copyright: $\odot 2021$ Hisham S. EIGabry
Funding: This research did not receive any financial Competing Interest: The authors have declared that no competing interest exists Open Access: This is an open-access article distribute under the terms of the Creative Commons Attribution-

\begin{abstract}
PURPOSE: This study aimed to compare patients' satisfaction with mandibular overdentures retained by threesplinted implants versus conventional complete denture wearers during a 7-year follow-up study period.

MATERIALS AND METHODS: Thirty edentulous male patients (mean age: 60 years) were carefully selected and divided into two equal groups. All patients received a new set of complete dentures. Group I patients received three implants in the anterior mandible and were connected after 3 months with bars, clips, and loaded. Group II patients received conventional complete dentures. Patients' satisfaction was recorded for both groups at 3 weeks (baseline) and after 1, 3, 5, and 7 years. Patients were then asked to grade their overdentures/dentures on a visual analog scale and written questionnaire to evaluate their overall satisfaction.

RESULTS: Satisfaction scores of Group I patients were found to be statistically significantly higher than that of Group II patients $(p<0.05)$ at 3,5 , and 7 years follow-up, meanwhile, no statistically significant difference was found at baseline or after 12 months.

CONCLUSION: The long-term results suggest that three-implant-retained mandibular overdenture with a clip-bar attachment appears to be a successful rehabilitation strategy which is superior to conventional dentures for patients with advanced ridge resorption.
\end{abstract}

\section{Introduction}

Transition from the dentulous to edentulous state, rehabilitated with or without implant-supported overdentures, is a path of special concern for many patients. Despite that, the dependence on removable dentures is still a reality of life for millions of people around the globe. However, the success of edentulism treatment with conventional complete dentures is still questionable regarding dentures retention/stability, impaired chewing ability, and suspected further mandibular bone resorption. As a matter of fact, edentulous patients' dissatisfaction with their complete dentures has been a dilemma for many decades [1]

On the other hand, enhancement of oral function with mandibular implant-retained overdenture can be an excellent treatment modality for edentulous patients who have mandibular complete dentures persistent problems although it may cause several prosthetic complications especially in the $1^{\text {st }}$ year of function [1].

While there have been several long-term studies on two- and four-implant-retained mandibular overdentures, there are no three-implant-retained mandibular overdentures long-term studies where the only available data are few case studies. The use of three implants is recommended in certain cases of high muscle attachments requiring higher retention or cases where forces on the anterior implants need to be minimized because of poor posterior ridge form. In such cases, the utilization of three implants produces a stable tripodal design, thereby greater stability can be achieved. It is the fact that the third implant allows for superstructure flexure reduction, less frequent screw loosening, and more efficient stress distribution, thus, enhancing crestal bone loss reduction [2], [3].

Patient satisfaction is an important factor that influences the overdenture/denture success. The status of the prosthesis, retention/stability, pain sensation, esthetics, hygiene maintenance, and chewing problems is the key factors which usually influence overall patient satisfaction [4], [5].

\section{Objective}

This study aimed to compare overall patients' satisfaction during a 7-year follow-up period with mandibular overdentures retained by three-splinted implants versus conventional complete denture wearers. 


\section{Materials and Methods}

Thirty edentulous male patients with a mean age of 60 years were selected from the Outpatient Prosthodontics Clinic, Faculty of Oral and Dental Medicine, Cairo University, Egypt. Exclusion criteria were insufficient bone volume to install three $13 \mathrm{~mm}$ interforaminal implants and insufficient interarch space. Patients with diabetes, osteoporosis, smokers, psychological problems of removable denture acceptance, gag reflex, absence of a maxillary complete denture, and medical or physical considerations that would seriously affect the surgical procedure (Group I) or the follow-up period were also excluded from the study. The inclusion criteria stipulated that patients must have been wearing dentures on a regular basis, being edentulous for a minimum of 3 years, and are capable of reading and writing.

Patients were divided into two equal groups, each of 15 patients to receive either three-implant-retained mandibular overdentures (Group I) or conventional complete set of dentures (Group II). For all patients, a new set of well-constructed dentures was made.

For Group I patients, three $13 \mathrm{~mm}$ implants (ScrewPlant $^{\mathrm{TM}}$ Spectra-System Dental Implants, CA 91301, USA) were inserted in the interforaminal region of the mandible using a standardized submerged surgical approach. After 3 months, implants were connected with bars (OT Multiuse Bar, RHEIN 83) leaving a 1.5-2 $\mathrm{mm}$ clearance space between the bar and residual ridge (Figure 1). Retentive clips (Yellow, RHEIN 83) were picked up intraorally with auto-polymerized acrylic resin (Figure 2). As for Group II patients, a new set of properly constructed complete dentures were delivered. All prosthetic procedures were performed by the same prosthodontist. Overall implants success was measured by absence of mobility, peri-implant radiolucency, pain or paresthesia, and progressive marginal bone loss. Patients were scheduled for follow-up visits to fill-up the questionnaire after 3 weeks (baseline), 1, 3, 5, and 7 years. All overdentures/dentures were adjusted and repaired as needed during the 7-year follow-up period. If the denture base adaptation was not acceptable for either group, a relining was performed and premature occlusal contacts were eliminated. Furthermore, loosened abutments and occlusal screws were tightened and loosened retentive clips were either changed or activated.
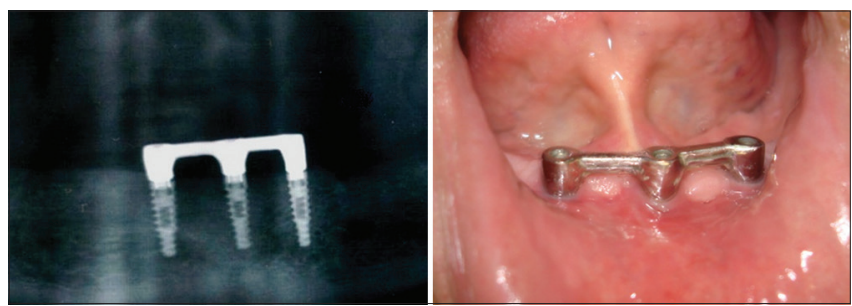

Figure 1: Three implants connected with bar attachment

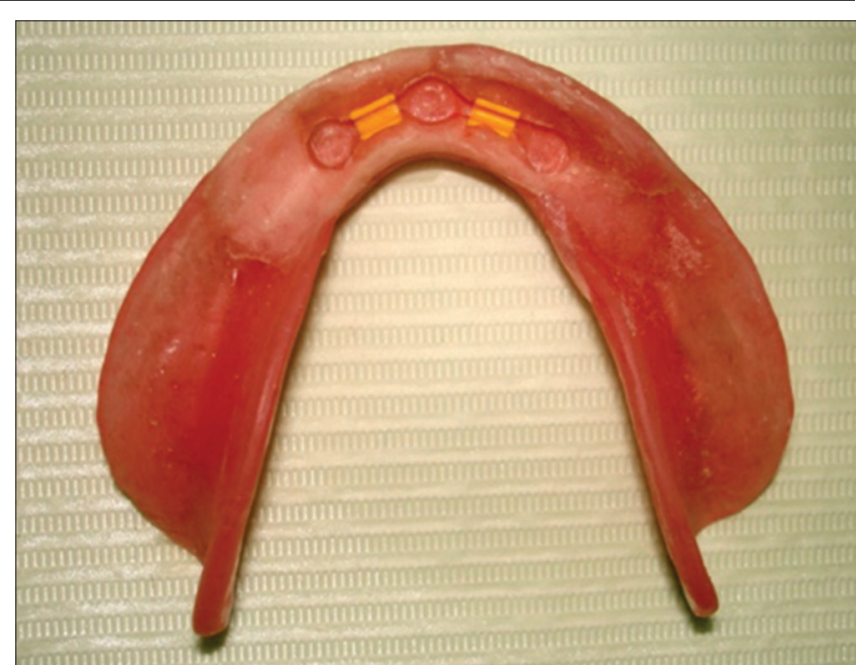

Figure 2: Retentive clips picked-up in denture fitting surface

\section{Patient satisfaction}

All patients were asked to complete a questionnaire which was given in Arabic language, recording nine aspects of patient satisfaction using a 0-100 mm visual analog scale (VAS). The scales ranged from completely satisfied to completely unsatisfied. The patients used the scales to record their personal opinions: General satisfaction, comfort, stability, speech, hygiene maintenance, esthetics, ability to chewing, pain, and retention. These factors were based on previously published patient satisfaction studies; the higher the score, the more satisfied the patient is. Evaluation of patient satisfaction for both groups was performed at 3 weeks (baseline), 1, 3, 5, and 7 years thereafter [6].

\section{Statistical analysis}

The primary outcome variables were patient preference and satisfaction ratings on the VAS. The satisfactionscoresforeach ofthedomains of the satisfaction questionnaires were entered into a spreadsheet and analyzed. Statistical analysis was performed using Statistical Package for the Social Sciences (SPSS) software (version 21, SPSS, Inc., Chicago, IL, USA). Variables were displayed as means \pm standard deviation (SD) was calculated. The Mann-Whitney U-test was used to assess the differences between means comparing the treatment options while Kruskal-Wallis non-parametric ANOVA was used to assess the effect of time on patient satisfaction. $p<0.05$ was considered to be statistically significant.

\section{Results}

\section{Patient dropout}

After 7 years, two patients had dropped out from each group. At year 3, a patient from Group I 
could not attend the follow-up because of a terrible car accident and a patient from Group II moved out of town. At year 5, two patients (one from each group) could not attend the evaluation process regularly for severe medical reasons. During the 7-year follow-up period, none of the implants failed.

\section{Patient satisfaction}

The mean values and VAS scores recorded for both groups along the different follow-up periods are shown in the following table. A mean satisfaction score was calculated as the mean value of the different parameters assessed for patient satisfaction and was used for comparison between groups (Table 1).

The results of the statistical analysis revealed a significant change in mean patient satisfaction with time in both Group I and Group II ( $p=0.02$ and $p \leq 0.01$, respectively). Meanwhile, the comparison between both groups at different data gathering points revealed a non-statistical significant difference in mean satisfaction score at baseline and after 12 months $(p=0.13$ and 0.09 , respectively). Nevertheless, a statistical significant difference in mean satisfaction score was found after 3 , 5 , and 7 years of overdenture/denture usage; Group I showing significant higher values for patient satisfaction as compared to Group II (Figures 3 and 4).

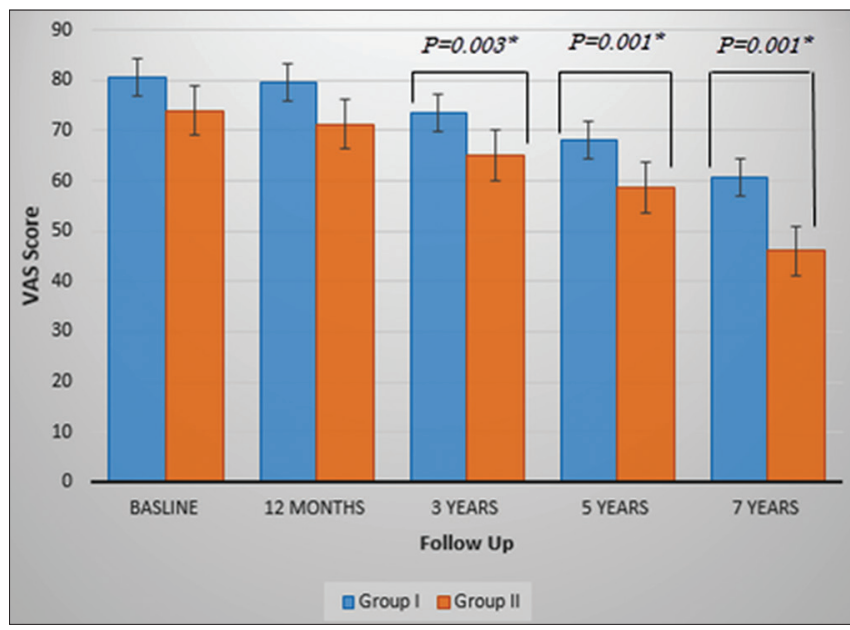

Figure 3: A bar chart showing the mean values of visual analog scale scores for the two groups; $p$ value is significant at $p \leq 0.05$.

*: Statistically significant difference between groups (Mann-Whitney U-test)

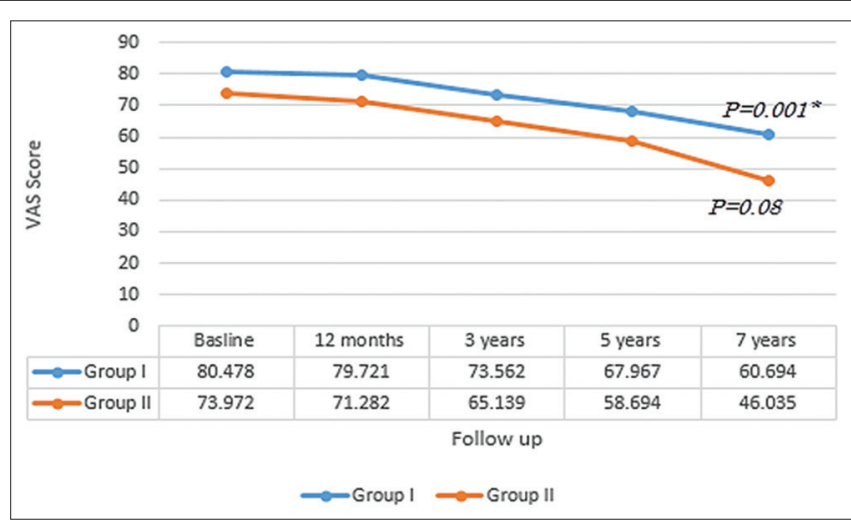

Figure 4: A line chart showing the mean values of visual analog scale scores for the two groups; $p$ value is significant at $p \leq 0.05$. *: Statistically significant difference between groups (Mann-Whitney U-test)

\section{Discussion}

It has been reported in several studies that patients who were treated with conventional dentures are far less satisfied than those who received mandibular implant-retained overdentures [2], [7], [8], [9], [10].

Most of the reports found, are randomized clinical trials and subject comparisons. In case of randomized clinical trials, patients are randomly divided into two equal groups receiving either new conventional complete dentures or mandibular implant-retained overdentures and the groups are compared. Whereas, in subject comparison cases, patients either compare their new and old dentures with each other or use their new dentures for a short period of time and then compare them to implants-retained overdentures. Nevertheless, our study, on the other hand, uniquely evaluates all patients after 7 years of dentures usage [7], [11].

Implant-retained overdentures appear to be a reliable treatment modality which is effective in minimizing most common denture complaints for edentulous patients. Furthermore, patients' satisfaction with mandibular implant-retained overdentures was clearly evident to be higher than patients wearing conventional dentures, which is in agreement with similar research studies. However, strict oral hygiene, regular maintenance, and scheduled recall appointments are the key of success for those overdenture patients. It

Table 1: Mean and stranded deviation of satisfaction scores for five data gathering points

\begin{tabular}{|c|c|c|c|c|c|c|c|c|c|c|c|c|c|c|c|c|c|c|c|c|}
\hline \multirow{3}{*}{$\begin{array}{l}\text { Follow-up } \\
\text { Group } \\
\text { Visual analog scale score }\end{array}$} & \multicolumn{4}{|c|}{ Baseline } & \multicolumn{4}{|c|}{12 months } & \multicolumn{4}{|c|}{3 years } & \multicolumn{4}{|c|}{5 years } & \multicolumn{4}{|c|}{7 years } \\
\hline & \multicolumn{2}{|c|}{ Group I } & \multicolumn{2}{|c|}{ Group II } & \multicolumn{2}{|c|}{ Group I } & \multicolumn{2}{|c|}{ Group II } & \multicolumn{2}{|c|}{ Group I } & \multicolumn{2}{|c|}{ Group II } & \multicolumn{2}{|c|}{ Group I } & \multicolumn{2}{|c|}{ Group II } & \multicolumn{2}{|c|}{ Group I } & \multicolumn{2}{|c|}{ Group II } \\
\hline & Mean & SD & Mean & SD & Mean & SD & Mean & SD & Mean & SD & Mean & SD & Mean & SD & Mean & SD & Mean & SD & Mean & SD \\
\hline General satisfaction & 79.8 & 20.6 & 69.8 & 18.5 & 81.5 & 16.1 & 65.5 & 12.3 & 76.4 & 16.5 & 63.2 & 19.2 & 71.4 & 13.2 & 59.5 & 14.3 & 63.8 & 18.9 & 52.1 & 17.6 \\
\hline Comf & 8 & 18.9 & & 16.2 & 80. & & & & & & & & & 16.3 & & & & & & 16.5 \\
\hline & & 14.2 & & & & & & & & & & & & 12 & & & & & & 18.5 \\
\hline Speech & 1.3 & 13.1 & 73.1 & 21.3 & 83.2 & 10.6 & & 20.2 & 75. & 16.5 & 69 & 16.9 & 70 & 18.1 & 59.0 & 14.8 & 62.8 & 19.7 & 42.1 & 19.7 \\
\hline & & & & & & & & & & & & & & & & & & & & 17.7 \\
\hline & 8 & 11.5 & 79.2 & 11.9 & 80 & & & 16.3 & 75. & 11.6 & & 18 & 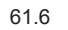 & 12.9 & 61 & 16.4 & 55 & 21.1 & 47.2 & 19.6 \\
\hline Ability to chew & 84.1 & 11.6 & 75.4 & 18.3 & 81.2 & 11.7 & 69.4 & 17.3 & 77.3 & 14.9 & 63.2 & 14.5 & 71.5 & 11.1 & 57.4 & 14.8 & 63.8 & 18.5 & 46.3 & 16.7 \\
\hline Pain & 8 & 16.4 & & 17.4 & 76.3 & 12.7 & & 12.5 & 70.4 & 15.4 & & 19.4 & 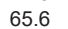 & 13.2 & & 13.5 & & 16.1 & & 18.5 \\
\hline & & 15. & & 18.7 & & 17 & & 11.2 & & 18. & & 16 & 68 & 12.2 & & 17.3 & & 18.6 & & 16.8 \\
\hline Mean satisfaction score & 80.48 & 16.3 & 73.97 & 17.4 & 79.72 & 13.54 & 71.28 & 16.4 & 73.56 & 17.21 & 65.14 & 18.32 & 67.97 & 14.3 & 58.69 & 16.01 & 60.69 & 18.91 & 46.03 & 18.92 \\
\hline
\end{tabular}


has been reported that lower satisfaction scores were recorded for women wearing dentures in comparison male patients, and therefore, women were excluded from this study [7], [10].

In this 7-year follow-up study, the basic scores for the mandibular overdentures retained with clip-bar attachment in comparison to conventional complete dentures are consistent with those obtained in other investigations using the same questionnaires and scale setup [12].

Mucosal tissue hyperplasia was the most commonly observed complication followed by periimplant mucositis under the bar attachment which was mainly due to patients poor oral hygiene. It is to be mentioned that the identified risk indicators of peri-implant diseases are plaque, smoking, history of periodontitis, width of the keratinized tissue, and function time of the implant. In addition to other factors as occlusal overloading, parafunctional habits, and improper implant position. Peri-implant mucositis is associated with an increased risk of becoming periimplantitis. Thus, routine follow-up of the implant patient with periodic assessment of plaque, calculus, pocket depth, and radiological evaluation for bone loss was strict and highly recommended [4], [13].

However, few patients complained of retention loss and almost all patients reported their satisfaction from both functional and esthetic points of view. Furthermore, the need for clip activation was observed in the some patients; $60 \%$ of clip activations happened during the first 3 years of service. It is to be mentioned that patients' clip/bar prosthetic satisfaction is generally not affected by the common implant prostheses technical complications [4], [14].

Only two patients in the overdenture group found their maxillary denture less comfortable which reflects the decrease of stability of the maxillary denture. However, instability of the maxillary denture with mandibular implantretained overdentures has been reported in number of studies. Nevertheless, others found no differences between mandibular overdenture and mandibular complete denture groups related to complaints about the maxillary denture [4], [14], [15], [16].

Opposing denture maintenance, such as rebasing and fracture of the maxillary denture, happened in $33 \%$ of the dentures opposing overdentures, indicating that the high force patients can exert with their overdentures, in agreement with the previous studies. However, patients with conventional complete dentures experienced less satisfactory experience related to their daily life denture usage as compared to patients with implant-retained overdentures [7], [16].

The present results confirm the established evidence showing a significantly improved satisfaction among edentulous patients with their prostheses when implants were used for retaining mandibular overdentures [5], [16], [17].

\section{Conclusion}

Within the limitations of this study design, regarding the sample size, gender selection, and the study period, it can be concluded that after 7 years follow-up period:

- Choosing implant-retained overdentures as a primary treatment option for edentulous patients appear to be very satisfactory regarding reduction of various denture complaints

The use of implants to retain and support mandibular overdenture improved patients comfort and selfconfidence in social interactions

- The long-term results suggest that threeimplant-retained mandibular overdenture with a clip-bar attachment appears to be a successful rehabilitation strategy which is superior to conventional dentures for patients with advanced ridge resorption.

\section{Ethical Approval}

This study was designed and approved by the Medical Research Ethical Committee (MREC Approval No. 13032) of National Research Centre, Cairo-Egypt, which is in accordance with Helsinki Declaration of 1975. All patients were informed about the practical steps of this study and signed written approval consent.

\section{Clinical trial registration}

This study was registered in Clinical Trials.gov PRS with ID: NCT04726540.

\section{References}

1. Awad MA, Rashid F, Feine JS. The effect of mandibular 2-implant overdentures on oral health-related quality of life: An international multicentre study. Clin Oral Implants Res. 2014;25(1):46-51. https://doi.org/10.1111/clr.12205 PMid:23735197

2. Geckili O, Bilhan H, Mumcu E, Dayan C, Yabul A, Tuncer N. Comparison of patient satisfaction, quality of life, and bite force between elderly edentulous patients wearing mandibular two implant-supported overdentures and conventional complete dentures after 4 years. Spec Care Dentist. 2012;32(4):136-41. https://doi.org/10.1111/j.1754-4505.2012.00258.x

PMid:22784321

3. Geckili O, Bilhan H, Mumcu E. Clinical and radiographic evaluation of three-implant-retained mandibular overdentures: A 3-year retrospective study. Quintessence Int. 2011;42(9):7218. https://doi.org/10.1111/j.1741-2358.2011.00531. 


\section{PMid:21909496}

4. Preciado A, Del Río J, Lynch CD, Castillo-Oyagüe R. A new, short, specific questionnaire (QoLIP-10) for evaluating the oral health-related quality of life of implant-retained overdenture and hybrid prosthesis wearers. J Dent. 2013;41(9):753-63. https:// doi.org/10.1016/j.jdent.2013.06.014

\section{PMid:23831418}

5. Boven GC, Raghoebar GM, Vissink A, Meijer HJ. Improving masticatory performance, bite force, nutritional state and patient's satisfaction with implant overdentures: A systematic review of the literature. J Oral Rehabil. 2015;42(3):220-33. https://doi.org/10.1111/joor.12241

\section{PMid:25307515}

6. Sánchez-Siles M, Ballester JF, Salazar N, Gómez FJ, Moraleja R. Long-term evaluation of quality of life and satisfaction between implant bar overdentures and conventional complete dentures: A 23 years retrospective study. Clin Implant Dent Relat Res. 2018;20(2):208-14. https://doi.org/10.1111/cid.12576 PMid:29239092

7. KutkutA, Bertoli E, Frazer R, Pinto-Sinai G, Hidalgo RF, Studts J. A systematic review of studies comparing conventional complete denture and implant retained overdenture. J Prosthodont Res. 2018;62(1):1-9. https://doi.org/10.1016/j.jpor.2017.06.004 PMid:28666845

8. Harris D, Höfer S, O'Boyle CA, Sheridan S, Marley J, Benington IC, et al. A comparison of implant-retained mandibular overdentures and conventional dentures on quality of life in edentulous patients: A randomized, prospective, within-subject controlled clinical trial. Clin Oral Implants Res. 2013;24(1):96103. https://doi.org/10.1111/j.1600-0501.2011.02368.x

\section{PMid:22111872}

9. Emami E, Thomason JM. In individuals with complete tooth loss, the mandibular implant-retained overdenture increases patient satisfaction and oral health related quality of life compared to conventional dentures. J Evid Based Dent Pract. 2013;13(3):946. https://doi.org/10.1016/j.jebdp.2013.07.003 PMid:24011002

10. Ahmad R, Chen J, Abu-Hassan MI, Li Q, Swain MV. Investigation of mucosa-induced residual ridge resorption under implantretained overdentures and complete dentures in the mandible. Int J Oral Maxillofac Implants. 2015;30(3):657-66. https://doi.

\section{org/10.11607/jomi.3844}

\section{PMid:26009917}

11. Nogueira TE, Dias DR, Leles CR. Mandibular complete denture versus single-implant overdenture: A systematic review of patient-reported outcomes. J Oral Rehabil. 2017;44(12):100416. https://doi.org/10.1111/joor.12550 PMid:28805255

12. Rokaya D, Srimaneepong V, Wisitrasameewon W, Humagain M, Thunyakitpisal P. Peri-implantitis update: Risk indicators, diagnosis, and treatment. Eur J Dent. 2020;14(4):672-82. https://doi.org/10.1055/s-0040-1715779 PMid:32882741

13. Sasada Y, Cochran DL. Implant-abutment connections: A review of biologic consequences and peri-implantitis implications. Int J Oral Maxillofac Implants. 2017;32(6):1296-307. https://doi. org/10.11607/jomi.5732 PMid:29140374

14. Cardoso RG, Melo LA, Barbosa GA, Calderon PD, Germano AR, Mestriner W Jr., et al. Impact of mandibular conventional denture and overdenture on quality of life and masticatory efficiency. Braz Oral Res. 2016;30(1):e102. https://doi.org/10.1590/18073107bor-2016.vol30.0102

PMid:27737356

15. Gonçalves F, Campestrini VL, Rigo-Rodrigues MA, Zanardi PR. Effect of the attachment system on the biomechanical and clinical performance of overdentures: A systematic review. J Prosthet Dent. 2020;123(4):589-94. https://doi.org/10.1016/j. prosdent.2019.03.024

PMid:31542217

16. Mendes FA, Borges TF, Gonçalves LC, de Oliveira TR, do Prado CJ, das Neves FD. Effects of new implant-retained overdentures on masticatory function, satisfaction and quality of life. Acta Odontol Latinoam. 2016;22(2):123-9.

PMid:27731481

17. Paleari AG, Oliveira NM Jr., Marin DO, Rodriguez LS, Filho JN, Pero AC, et al. One-year prospective clinical study comparing patient satisfaction and masticatory performance of mandibular overdentures supported by one versus two implants. J Appl Oral Sci. 2018;26:e20160628. https://doi. org/10.1590/1678-7757-2016-0628

PMid:30304120 